\title{
The vitamin A and mortality paradigm: past, present, and future
}

\author{
By Richard D. Semba
}

\begin{abstract}
Vitamin A deficiency contributes to the morbidity and mortality from some infectious diseases. Empirical observations and trials from the early twentieth century led to the paradigm that improvement of vitamin A status could reduce morbidity and mortality among women and children. Many seminal observations of vitamin A deficiency and infection were made in Scandinavia. International organizations in the 1930s and 1940s emphasized adequate vitamin A status to prevent morbidity and mortality. With improvement of nutrition and hygiene in Europe and the United States, vitamin A deficiency largely disappeared, and attention later turned towards developing countries. Over one hundred clinical trials have addressed the impact of vitamin A on infectious disease morbidity and mortality and show that adequate vitamin A status is important in measles and diarrheal disease but not in non-measles pneumonia. Current studies extend investigations of the role of vitamin A to malaria, tuberculosis, and human immunodeficiency virus infection.

Key words: Immunity, infection, morbidity, mortality, vitamin A
\end{abstract}

\section{Introduction}

Vitamin A deficiency is a major public health problem in at least sixty developing countries worldwide, and an estimated 253 million preschool children are affected by vitamin A deficiency (1). Pregnant women and women of childbearing age also constitute a high risk group for vitamin A deficiency in developing countries. Vitamin A plays an important role in immune function, growth, reproduction, and vision. Clinical trials in the last fifteen years showed that improving vitamin A status of preschool children through supplementation or fortification can reduce morbidity and mortality, specifically of diarrheal diseases but not acute lower respiratory disease $(2,3)$. Vitamin A supplementation also reduced morbidity and mortality in children with acute measles (4) and seems to reduce mortality related to pregnancy (5). Empirical observations and clinical trials conducted as early as the 1920s and 1930s suggested that vitamin A could reduce infectious disease morbidity and mortality, and the origins of these ideas and earlier clinical practice have largely gone unacknowledged during the last fifteen years (6). Recent trials from developing countries have further reinforced the idea that vitamin A reduces morbidity and mortality from infectious diseases - a paradigm that was established by the early part of the twentieth century.

\section{Early uses of vitamin A as "anti-infective" therapy}

In the nineteenth century, physicians at Brompton Hospital in London found that vitamin A - in the form of cod-liver oil - could reduce morbidity and mortality in patients with tuberculosis (7). At the time, it was not known that the active agent in cod-liver oil was vitamin $\mathrm{A}$, but it was widely concluded from clinical experience and comparison with historical controls that this extremely potent source of vitamin A was an effective therapy. As is not uncommon in the history of medicine, the intrinsic value of certain therapies was established early through trial and error, without evaluation through a randomized, controlled clinical trial. Cod-liver oil was widely used as "anti-infective" therapy against tuberculosis, like foxglove was used for heart

Richard D. Semba, M.D., M.P.H., 550 North Broadway, Suite 700, Baltimore MD 21205, U.S.A. E-mail: rdsemba@jhmi.edu failure, even though the active agents were not named, isolated, and synthesized until hundreds of years later. Other parallels can be made with the early use of lemons and oranges for scurvy in the centuries prior to the vitamin hypothesis. Several physicians claimed to have "discovered" that cod-liver oil reduced mortality, and many disputes arose about the priority of this claim. However, the use of fish liver oils for infectious diseases had already been practiced for hundreds of years, as is evident in Arabic, Roman, and Greek medical texts.

\section{Towards the characterization of vitamin A}

The existence of vitamin A was demonstrated through a long series of steps that spanned a period of over one hundred and thirty years. In 1816, François Magendie found that dogs raised on sugar and water alone developed corneal ulcers and died (8). In the late nineteenth century at the University of Dorpat, Nicolai Lunin (9) and C. A. Socin (10) showed that mice could not survive on purified protein, fat, carbohydrate, and mineral salts alone, but were able to survive for extended periods if supplemented with milk or egg yolk. Cornelis Pekelharing (11) and Frederick Hopkins (12) both conducted studies that also suggested there was something essential in milk that supported growth and survival, and Hopkins believed these "accessory factors" were necessary for life. In 1911, Wilhelm Stepp extracted lipids from milk with alcohol-ether that appeared to contain the active substance $(13,14)$ and in 1913 at the University of Wisconsin, Elmer McCollum and Marguerite Davis extracted the lipids with ether from cod-liver oil, concluding "our observation ...strongly supports the belief that there are certain accessory articles in certain food-stuffs which are essential for normal growth for extended periods" (15). At Yale University, Thomas Osborne and Lafayette Mendel made the seminal observation that infectious diseases in vitamin A-deficient animals were quickly alleviated by introduction of butter-fat in the diet $(16,17)$. In 1916, this growth-promoting and anti-infectious substance was termed "fat-soluble A" (18).

Harry Steenbock and colleagues proposed in 1919 that there was a connection between yellow plant pigments ("carotin") and vitamin A, an observation suggested by the appearance of vitamin A deficiency in a rat colony when white corn was substituted 
for yellow corn in the regular animal feed (19). Carotin had growth-promoting (20) and "anti-infective" (21) properties similar to vitamin A. Thomas Moore found that purified carotin restored growth and cured ophthalmia and concluded that carotin was a precursor to vitamin $\mathrm{A}(22,23)$. The structure of vitamin $\mathrm{A}$ was deduced in 1931 by Paul Karrer and colleagues $(24,25)$ and vitamin A was finally crystallized in 1937 (26). During this long period leading to the biochemical characterization of vitamin A, important clinical observations were being made among children.

\section{Observations from Denmark}

From 1909 to 1920 , the Danish ophthalmologist, Olaf Blegvad documented cases of xerophthalmia, or clinical vitamin A deficiency, among children in Denmark (28). From 1911 to 1917, there was a strong, gradual increase in the number of cases of keratomalacia, the most severe eye lesion of vitamin A deficiency, followed by a decline in 1918 and 1919 and then an increase in 1920. During the same period in Sweden, there was no epidemic of xerophthalmia. Blegvad showed that the export of butter and cheese from Denmark and increased consumption of margarine within the country were linked with the increase in vitamin A deficiency. The manufacture of margarine ceased in 1917 after a German submarine blockade halted importation of raw materials, and butter, which was produced in Denmark at an expensive price, was then rationed at a more affordable cost for the poor after December 21, 1917. On May 1, 1919, butter rationing ceased (Figure 1) (28). The mortality rate observed among 434 children with xerophthalmia was about $21 \%$, with the highest mortality noted among younger infants. The high mortality of children was attributed to infections and the lack of vitamin A, and it resembled the infections and mortality found in animals experimentally raised on a vitamin A-deficient diet (28).

Carl Edvard Bloch (1872-1952), a pediatrician in Copenhagen, also dealt with the epidemic of xerophthalmia and provided important descriptions of the epidemiology of vitamin $\mathrm{A}$ deficiency (29). Bloch observed that the number of cases of children admitted with xerophthalmia at the State Hospital in Copenhagen rose from 1912 to 1917 , then dropped dramatically in 1918 (Figure 2) (30). The abrupt decline in cases of xerophthalmia in 1918 coincides with butter rationing for the poor in 1918 (Figure 1). Bloch noted that xerophthalmia was associated with lack of milk and green vegetables in the diet, and that children with xerophthalmia had retarded growth. He concluded that vitamin A deficiency was characterized by a decline in immunity, increased severity of infections, and a higher risk of death. Child mortality was reduced by providing foods containing vitamin A. Bloch advocated the provision of milk, cream, and butter to reduce eye disease, promote growth and development, and reduce infectious diseases of children (29).

The concerns about vitamin A deficiency clearly extended beyond children who had xerophthalmia, or clinical vitamin A deficiency. The concept of subclinical vitamin A deficiency was widely discussed. Based upon the observations in Denmark and animal studies, Erik Widmark (1889-1945), Professor of Medical and Physiological Chemistry at the University of Lund, concluded in The Lancet "...there must be in a population in which xerophthalmia occurs a much larger number of cases in which the deficiency in vitamin A, without producing the eye disease, is the cause of a diminished resistance to infections, of general debility, and of malnutrition" (31). A state of subclinical vitamin A deficiency was acknowledged as "the borderline between health and disease" where a child would appear healthy, but in the face of an infection would do less well because of an underlying vitamin deficiency (32). The emphasis shifted from targeting children with xerophthalmia to ensuring adequate vitamin A status of children in populations.
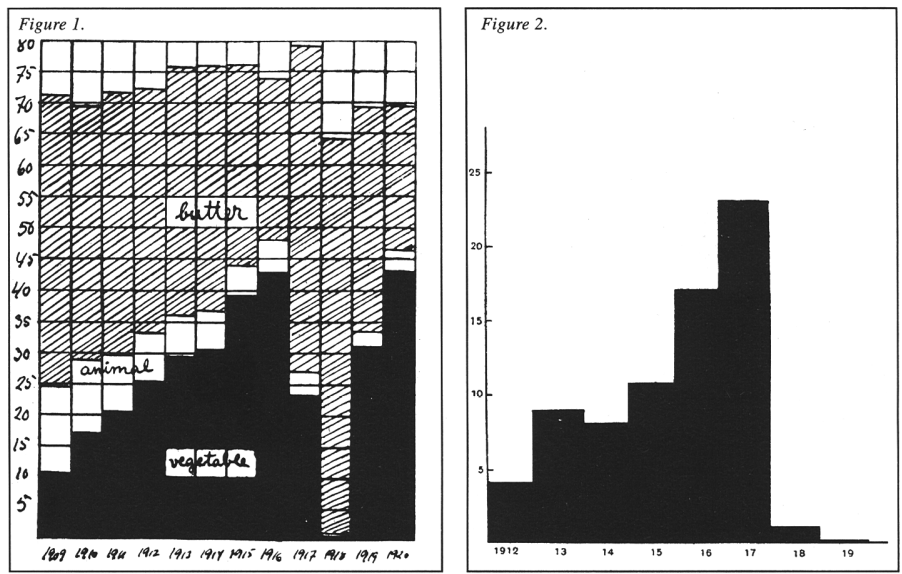

Figure 1. Original figure from Olaf Blegvad's study in 1924 showing butter and margarine consumption from 1909 to 1920 . Relative amount of butter used each year (oblique lines); substitutes made from animal fats (white spaces); and vegetable fat substitutes (black spaces) (28).

Figure 2. Original figure from Carl Bloch's study in 1921, showing the number of cases of xerophthalmia admitted to the State Hospital, Copenhagen, 1912-1919 (30).

\section{Vitamin A as the "anti-infective" vitamin}

Vitamin A became known as the "anti-infective" vitamin, and from 1920 through 1940, vitamin A underwent considerable evaluation through at least thirty therapeutic trials, from dental caries and pneumonia to puerperal sepsis and measles. These studies were conducted during a period when there was an increased awareness of the problem of infant and child mortality in Europe and the United States (6). These trials were conducted in places such as England, Sweden, Spain, France, the United States, and South Africa. Among the notable findings of these trials was that vitamin A supplementation reduced mortality from measles in children (33) and reduced the morbidity of puerperal sepsis $(34,35)$. With the introduction of antibiotics in the mid-1930s, greater attention was paid to sulfa antibiotics and later penicillin, and there was an accompanying decline in the number of vitamin A trials. Vitamin A became a mainstream preventive measure: cod-liver oil was part of the morning routine for millions of children - a practice promoted by physicians and popularized by the pharmaceutical industry (6). Much of the world's supply of cod-liver oil, and hence, vitamins A and D, came from the commercial fisheries of Norway and Newfoundland. Other public health measures that were taken to improve vitamin A status of children were institution of school milk programs, fortification of milk and margarine with vitamin $\mathrm{A}$, and the promotion of home gardening $(6,36,37)$.

The idea that vitamin A deficiency could increase susceptibility to infection and increase morbidity and mortality was widely accepted and influenced public health efforts in the first five decades of the twentieth century. Major health organizations, including the League of Nations Health Committee, the Women's Foundation for Health, the Council of British Societies for Relief Abroad, and the Medical Research Council of Great Britain, emphasized the importance of ensuring adequate vitamin A intake in populations in order to increase resistance to infectious diseases (38-41). These concerns were also echoed in nutrition textbooks and research monographs at the time by such influential nutritionists, physicians, and public health leaders such as Robert McCarrison (42). Jack Cecil Drummond (43) and Edward Mellanby (44) in England, Georges Mouriquand (45) in France, Giambattista Bietti (46) in Italy, Robert Ammon (47) in Germany, and Henry Clapp Sherman (48) Mary Swartz Rose (49) and Wilson Smillie (50) in the United States. 
Table 1. Some important trials of vitamin $A$ and infectious diseases.

Location Date Subjects Observation

Ref

England 1871 adults cod-liver oil reduces tuberculosis mortality

England 1931 women vitamin A reduces morbidity of puerperal sepsis

England 1932 children vitamin A reduces measles mortality

Indonesia 1986 children vitamin A reduces diarrheal mortality

S Africa 1990 children vitamin A reduces measles mortality

S Africa 1995 children vitamin A reduces morbidity in children born to HIV+ mothers

Tanzania 1999 children vitamin A reduces mortality in HIV + children

$\mathrm{PNG}^{1} 1999$ children vitamin A reduces malaria morbidity

Nepal 1999 women vitamin A or $\beta$-carotene reduce mortality related to pregnancy

${ }^{1}$ Papua New Guinea

\section{Attention turns towards developing countries}

With improvements in nutrition, hygiene, and living standards, vitamin Adeficiency gradually disappeared from Europe and the United States. The Joint Food and Agricultural Organization/ World Health Organization Expert Committee on Nutrition focused on vitamin A deficiency as a public health problem in developing countries in the 1950s, and in 1962 a world-wide survey of xerophthalmia was organized by the World Health Organization (51). The main investigators of the global survey, H.A.P.C. Oomen, Donald S. McLaren, and Humberto Escapini, showed that vitamin A deficiency remained a major health problem in many parts of the world, especially in south Asia, southeast Asia, sub-Saharan Africa, and Central America. These investigators recognized a vicious cycle of vitamin A deficiency and infection: "Not only may deficiency of vitamin A itself play an important role in lowering the resistance to infection... but infectious diseases themselves predispose to and actually precipitate xerophthalmia." In their influential work, Interactions of Nutrition and Infection, Nevin S. Scrimshaw, Carl E. Taylor, and John E. Gordon reviewed the large body of clinical and experimental evidence that had accumulated by 1968 and concluded: "One of the first recognized features of avitaminosis A, increased susceptibility to infection, has had strong confirmation" (52).

Nutrition surveys by the Interdepartmental Committee on Nutrition for National Defense of the U.S. National Institutes of Health, also conducted during the late 1950s and early 1960s, assessed vitamin A deficiency in many populations around the world. Vitamin A deficiency was considered a major health problem in Jordan (53) Ethiopia (54) Vietnam (55) Thailand (56) Lebanon (57) and East Pakistan (Bangladesh) (58). These surveys defined vitamin A deficiency as a public health problem if more than $5 \%$ of the population had plasma or serum vitamin A concentration $<0.35 \mu \mathrm{mol} / \mathrm{L}$ or more than $15 \%$ had concentrations $<0.70 \mu \mathrm{mol} / \mathrm{L}$ (59). Nutritional surveys conducted in Central America and Panama from 1965 to 1967 showed that vitamin A deficiency was widespread (60). In 1974, vitamin A fortification of sugar was implemented in Guatemala after strong advocacy by Guillermo Arroyave of the Institute of Nutrition of Central America and Panama (INCAP). The underlying rationale for such a far-reaching program was that vitamin A fortification would improve growth and resistance to infectious diseases in children (61).
During the late 1960s, Johanna ten Doesschate conducted epidemiological investigations in Indonesia that identified risk factors for xerophthalmia, including inadequate dietary intake of vitamin A and carotenoids, Ascaris infection, diarrheal disease, tuberculosis, measles, artificial feeding, prematurity, and lower socioeconomic status (62). The main cause of blindness among infants and young children in Indonesia was vitamin A deficiency, and follow-up of small children who had become blind showed that about $30 \%$ had subsequently died (62). In the late 1970 s, the Indonesian government began to consider vitamin A fortification of either wheat flour, sugar, or monosodium glutamate (MSG) (63). After further deliberation, of the three, only monosodium glutamate was considered a suitable carrier. Concern was raised by Indonesian government officials that fortification of MSG would appear to be government endorsement of a commercial product. An analysis by Carl Fritz at Helen Keller International in 1982 showed that fortification of monosodium glutamate, even if only $10 \%$ effective, would be cost effective in reducing mortality of an estimated 20,000 Indonesian children each year (63)

\section{Further clinical trials of vitamin $A$}

Through a national survey conducted in 1977-1978 in Indonesia, children with Bitot's spots and night blindness were noted to have a higher risk of mortality in 1983 (64) sparking further vitamin A clinical trials in the 1980s and 1990s $(2,65)$. There have been at least seventy clinical trials conducted in the last fifteen years that have evaluated the potential effect of improving vitamin A status on morbidity and mortality from infectious diseases. These trials were conducted in such places as Indonesia, India, Nepal, Sudan, Ghana, Chile, Guatemala, Bangladesh, Peru, and Brazil $(2,66)$. The contemporary trials revisit many of the same issues that were addressed in vitamin A trials conducted in the 1920s and 1930s (6). Recently, trials have been conducted to investigate the impact of vitamin A on measles, diarrheal disease, acute lower respiratory infection, respiratory syncytial virus infection, malaria, tuberculosis, human immunodeficiency virus (HIV) infection, maternal mortality, infant mortality, and infections in older adults. The types of interventions with vitamin A include community-based high dose supplementation, disease-targeted high dose supplementation, low dose daily supplementation, weekly supplementation, and fortification of monosodium glutamate $(2,66)$. The hospital and community-based trials have shown that supplementation or fortification reduces the morbidity and mortality of diarrheal disease and measles, but has no apparent impact upon acute lower respiratory infections (Table 1$)(2,3,66)$.

It is not clear why vitamin A supplementation does not improve morbidity and mortality from acute lower respiratory infections, and the lack of effect may be related to the type of immune responses involved (67) the age of the children, and other coexisting micronutrient problems, such as zinc deficiency. There is new evidence that vitamin A supplementation may reduce mortality for infants under the age of six months $(68,69)$. Vitamin A supplementation appears to reduce the morbidity of malaria and improve some clinical outcomes among adults and children with HIV infection (66,70,71-74). Other studies have focused on the impact of vitamin A supplementation upon growth $(75,76)$.

The World Health Organization currently recommends high dose vitamin A supplementation for children with xerophthalmia, acute measles, and diarrheal disease in developing countries where vitamin A deficiency is a public health problem (1). Some developing countries have adopted programs of intermittent, high dose vitamin A capsule distribution for infants and children, a measure that may reduce diarrheal morbidity and mortality and is largely considered a temporary solution until other remedies 
can be found (66). In a sense, the contemporary distribution of vitamin A capsules to children in the community in developing countries resembles the widespread home use of cod-liver oil by the teaspoon or capsule for children in the early half of the twentieth century in Europe and the United States. Nowadays, a return to cod-liver oil is no longer a viable option: the cod fisheries have nearly been depleted in the North Atlantic, and synthetic vitamin $\mathrm{A}$ is a relatively inexpensive source for supplements or fortification.

\section{The vitamin A gap}

In developed countries there is a high consumption of preformed vitamin A in meat, dairy, and vitamin A-fortified foods, whereas in developing countries there is a high consumption of provitamin A carotenoids in fruits and vegetables (77). Recent evidence suggests that dark green leafy vegetables may not be as good a source of vitamin A as previously believed, due to low bioavailability $(78,79)$. In the 1980 s, conventional wisdom held that green leafy vegetables, and hence vitamin A, were everywhere in tropical environments: the rural poor only needed some dietary education and to increase their consumption of these plant sources of vitamin A. This concept has recently been uprooted, so to speak, based upon recent studies from Indonesia that have challenged this assumption (78). Although changes in dietary and horticultural practices may be expected to improve nutrition in women and children, these reforms may not completely close the gap. Efforts are also being made to fortify food products with vitamin $A$, such as sugar in Zambia, Guatemala and other Central American countries, margarine in the Philippines (80) instant noodles in Indonesia, and wheat flour in various countries $(77,80)$. These measures may help to overcome insufficient dietary intake of vitamin A in populations where consumption of meat and dairy products is low. Treatment for intestinal parasites such as Ascaris lumbricoides may also help improve the vitamin A status of children who consume a diet high in pro-vitamin A carotenoids (81).

\section{Too much of a good thing?}

Recent studies suggest that high dose vitamin A supplementation may have adverse consequences for some children who are not malnourished $(82,83)$. In a study conducted in Dar Es Salaam, Tanzania, children hospitalized with pneumonia received high dose vitamin A supplementation, and after discharge, they were monitored for diarrheal and respiratory disease. Vitamin A supplementation was associated with a higher rate of diarrheal disease among children who were better nourished, whereas a reduction in diarrheal morbidity was noted among wasted children. In an accompanying editorial, Jeffrey Griffiths has termed this effect the vitamin A paradox (57). A recent controlled clinical trial conducted in Quito, Ecuador also suggested that weekly vitamin A supplementation to children, aged 6-36 months, significantly reduced the incidence of acute lower respiratory infections in underweight (weight-for-age $\mathrm{Z}$ score $<-2$ ) children but significantly increased the incidence of acute lower respiratory infections in normal weight children (weightfor-age $Z$ score $>-1$ ) compared with placebo (83). These observations suggest that more cautious monitoring of high dose vitamin A capsule distribution programs is needed, especially in countries that are undergoing rapid demographic change and a nutrition transition towards that of developed countries.

\section{Future directions}

Future studies are addressing some of the final gaps in knowledge regarding the potential for vitamin A supplementation to reduce morbidity and mortality from infectious diseases. Ongoing trials will help to determine whether vitamin A supplementation can reduce morbidity and mortality in individuals with tuberculosis and in those with HIV infection. Other studies are attempting to replicate the finding that weekly vitamin $A$ or $\beta$-carotene supplementation can reduce pregnancyrelated mortality (5). Further investigation is needed to address the impact of vitamin A supplementation on the morbidity and mortality of Plasmodium falciparum malaria (71). The biological mechanisms by which vitamin A enhances immunity to infection are being studied mostly through experimental animal models (85). Taking clues from the field of cancer research $(86,87)$ various synthetic retinoids may eventually find application as primary or adjunct treatment for infectious diseases.

Given that multiple deficiencies of micronutrients often occur simultaneously and that many micronutrients act synergistically, clinical trials with daily, multi-micronutrient supplements can be expected to largely supplant single micronutrient interventions with vitamin $\mathrm{A}$ in developing countries. $88 \mathrm{An}$ area that begs much further investigation is the impact of home gardening on nutritional status and resistance to infection, as in the long run, food-based approaches will likely be more sustainable than vertical programs of supplement distribution. Much activity is now being focused on food-based approaches, such as community home gardening projects $(89,90)$ and complementary programs for deworming (81). If the historical record provides any guidance, a variety of approaches will be needed to combat vitamin A deficiency in developing countries, and improved vitamin A status will likely be accompanied by reduced morbidity and mortality from diarrheal disease, measles, and other infections.

\section{REFERENCES}

1. World Health Organization/UNICEF: Global prevalence of vitamin A deficiency. Micronutrient Deficiency Information System Working Pape 2. World Health Organization, Geneva 1995.

2. Beaton GH, Martorell R, L'Abbe KA, et al: Effectiveness of Vitamin A Supplementation in the Control of Young Child Morbidity and Mortality in Developing Countries. ACC/SCN State-of-the-Art Nutrition Policy Discussion Paper No. 13, United Nations, New York 1993.

3. The Vitamin A and Pneumonia Working Group: Potential interventions for the prevention of childhood pneumonia in developing countries: a metaanalysis of data from field trials to assess the impact of vitamin A supplementation on pneumonia morbidity and mortality. Bull WHO 1995 73:609-19.

4. Hussey GD, Klein, M: A randomized, controlled trial of vitamin A in children with severe measles. N Engl J Med 1990;323:160-4.

5. West KP, Katz J, Khatry SK, et al: Double blind, cluster randomised trial of low dose supplementation with vitamin A or beta carotene on mortality related to pregnancy in Nepal. BMJ 1999;318:570-5.

6. Semba RD: Vitamin A as "anti-infective" therapy, 1920-1940. J Nutr 1999 129:783-91

7. Williams CJB, Williams CT: Pulmonary Consumption: Its Nature, Varieties, and Treatment with an Analysis of One Thousand Cases to Exemplify Its Duration. Henry C. Lea, Philadelphia 1871.

8. Magendie F: Mémoire sur les propriétés nutritives des substances qui ne contiennent pas d'azote. Bull Sci Soc Phil Paris 1816;4:137-8.

9. Lunin N: Über die Bedeutung der anorganischen Salze für die Ernährung des Thieres. Zeitschr Physiol Chemie 1881;5:31-9.

10. Socin CA: In welcher Form wird das Eisen resorbirt? Zeitschr Physiol Chemie 1891;15:93-139.

11. Pekelharing CA: Over onze kennis van de waarde der voedingsmiddelen uit chemische fabrieken. Nederl Tijdschr Geneeskunde 1905;41:111-24.

12. Hopkins FG: Feeding experiments illustrating the importance of accessory factors in normal dietaries. J Physiol 1912;44:425-60.

13. Stepp W: Experimentelle Untersuchungen über die Bedeutung der Lipoide für die Ernährung. Zeitschr Biol 1911;57:136-70

14. Wolf G, Carpenter KJ: Early research into the vitamins: the work of Wilhelm Stepp. J Nutr 1997;127:1255-9.

15. McCollum EV, Davis M: The necessity of certain lipins in the diet during growth. J Biol Chem 1913;15:167-75.

16. Osborne TB, Mendel LB: Feeding Experiments with Isolated FoodSubstances. Publication 156. Carnegie Institute of Washington, Washington, D. C, 1911

17. Osborne TB, Mendel LB: The relationship of growth to the chemical constituents of the diet. J Biol Chem 1913;15:311-26.

18. McCollum EV, Kennedy C: The dietary factors operating in the production of polyneuritis. J Biol Chem 1916:24:491-502.

19. Steenbock $\mathrm{H}$ : White corn vs. yellow corn and probable relation between the fat-soluble vitamine and yellow plant pigments. Science 1919;50:352-3. 
20. Euler B von, Euler H von, Hellström H: Resemblance of action of lipochromes to that of vitamin A.Biochem Zeitschr 1928;203:370-84.

21. Green HN, Mellanby E: Carotene and vitamin A: the anti-infective action of carotene. Brit J Exp Pathol 1930;11:81-9.

22. Moore T: The relation of carotin to vitamin A. Lancet 1929;2:380-1.

23. Moore T: Absence of liver oil vitamin A from carotene; conversion of carotene to vitamin A in vivo. Biochem J 1930;24:692-702.

24. Karrer P, Morf R, Schöpp K: Zur Kenntnis des Vitamins-A aus Fischtranen. Helv Chim Acta 1931;14:1036-40.

25. Karrer P, Morf R, Schöpp K: Zur Kenntnis des Vitamins-A aus Fischtranen II. Helv Chim Acta 1931;14:1431-6.

26. Holmes HN, Corbet RE: The isolation of crystalline vitamin A. J Am Chem Soc 1937;59:2042-7.

28. Blegvad O: Xerophthalmia, keratomalacia and xerosis conjunctivae. Am J Ophthalmol 1924;7:89-117.

29. Bloch CE: Blindness and other diseases in children arising from deficient nutrition (lack of fat soluble A factor). Am J Dis Child 1924;27:139-48.

30. Bloch CE: Clinical investigation of xerophthalmia and dystrophy in infants and young children (xerophthalmia et dystrophia alipogenetica). J Hygiene $1921 ; 19: 283-303$

31. Widmark E: Vitamin-A deficiency in Denmark and its results. Lancet 1924;1:1206-9.

32. Cramer W: An address on vitamins and the borderland between health and disease. Lancet 1924;1:633-40.

33. Ellison JB: Intensive vitamin therapy in measles. Brit Med J 1932;2:708-11.

34. Green HN, Pindar D, Davis G, Mellanby E: Diet as a prophylactic agent against puerperal sepsis. Brit Med J 1931;2:595-8.

35. Cameron SJ: An aid in the prevention of puerperal sepsis. Trans Edinburgh Obstet Soc 1931;52:93-103.

36. Newman G: The Building of a Nation's Health. Macmillan, London 1939

37. Tucker DM: Kitchen Gardening in America: a History. Iowa State University Press, Ames, Iowa 1993.

38. Mixed Committee of the League of Nations: The Relation of Nutrition to Health, Agriculture and Economic Policy. Document A.13.1937.II.A. League of Nations, Geneva 1937

39. Rose MS: Choosing food for health. In: Handbook on Positive Health. [no editor] Revised edition. Women's Foundation for Health, New York 1928: 114-132.

40. Council of British Societies for Relief Abroad: Nutrition and Relief Work: Handbook for the Guidance of Relief Workers. Oxford University Press, London 1945.

41. Medical Research Council: Vitamins: a Survey of Present Knowledge. Special Report Series, No. 167. His Majesty's Stationery Office, London 1932.

42. McCarrison R: Studies in Deficiency Disease. Henry Frowde and Hodder \& Stroughton, London 1921

43. Drummond JC, Hilditch TP: The Relative Values of Cod Liver Oils from Various Sources. His Majesty's Stationery Office, London 1930.

44. Mellanby E: Nutrition and Disease: the Interaction of Clinical and Experimental Work. Oliver and Boyd, Edinburgh 1934

45. Mouriquand G: Vitamines et carences alimentaires. Albin Michel, Paris 1942

46. Bietti G: Le Vitamine in Oftalmologia. Licinio Cappelli, Bologna 1940.

47. Ammon R, Dirscherl W: Fermente Hormone Vitamine und die Beziehungen dieser Wirkstoffe zueinander. Georg Thieme, Leipzig 1938.

48. Sherman HC: The Science of Nutrition. Columbia University Press, New York 1943.

49. Rose MS: The Foundations of Nutrition. Macmillan, New York 1927

50. Smillie WG: Public Health Administration in the United States. Second edition. Macmillan, New York 1940.

51. Oomen HAPC, McLaren DS, Escapini H: Epidemiology and public health aspects of hypovitaminosis A. Trop Geogr Med 1964; 4: 271-315.

52. Scrimshaw NS, Taylor CE, Gordon JE: Interactions of Nutrition and Infection. World Health Organization, Geneva 1968.

53. Interdepartmental Committee on Nutrition for National Defense: The Hashemite Kingdom of Jordan Nutrition Survey on Infants and Preschool Children in Jordan, November 1962-October 1963. National Institutes of Health, Bethesda, 1964.

54. Interdepartmental Committee on Nutrition for National Defense: Ethiopia Nutrition Survey. National Institutes of Health, Bethesda 1959

55. Interdepartmental Committee on Nutrition for National Defense: Republic of Vietnam Nutrition Survey, October-December 1959. National Institutes of Health, Bethesda 1960.

56. Interdepartmental Committee on Nutrition for National Defense: The Kingdom of Thailand Nutrition Survey, October-December 1960. National Institutes of Health, Bethesda 1962.

57. Interdepartmental Committee on Nutrition for National Defense: Republic of Lebanon Nutrition Survey, February-April 1961. National Institutes of Health, Bethesda 1962

58. Interdepartmental Committee on Nutrition for National Defense: Pakistan Nutrition Survey of East Pakistan, March 1962-January 1964. National Institutes of Health, Bethesda 1966.

59. Interdepartmental Committee on Nutrition for National Defense: Manual for Nutrition Surveys. Second edition. National Institutes of Health, Bethesda 1963

60. Institute of Nutrition of Central America and Panama: Nutritional Evaluation of the Population of Central America and Panama: a Regional
Summary. DHEW Publication HSM 72-8120, U.S. Department of Health, Education and Welfare, Washington, D.C. 1972

61. Arroyave $\mathrm{G}$ : The program of fortification of sugar with vitamin $\mathrm{A}$ in Guatemala. Some factors bearing on its implementation and maintenance. In: Scrimshaw NS, Wallerstein MB. eds. Nutrition Policy Implementation: Issues and Experience. Plenum Press, New York 1982:75-88.

62. Doesschate J ten: Causes of blindness in and around Surabaja, East Java, Indonesia. Doctoral thesis. University of Jakarta, Jakarta, Indonesia 1968.

63. Gershoff SN: Food fortification. In: Scrimshaw NS, Wallerstein MB, eds Nutrition Policy Implementation: Issues and Experience. Plenum Press, New York 1982:61-74.

64. Sommer A, Tarwotjo I, Hussaini G, Susanto D: Increased mortality in children with mild vitamin A deficiency. Lancet $1983: 2 \cdot 585-8$.

65. Sommer A, Tarwotjo I, Djunaedi E, et al: Impact of vitamin A supplementation on childhood mortality: a randomized controlled community trial. Lancet 1986;1:1169-73.

66. Villamor E, Fawzi WW: Vitamin A supplementation: implications for morbidity and mortality in children. J Inf Dis 2000;182(suppl 2):S122-33.

67. Cui D, Moldoveanu Z, Stephensen CB: High-level dietary vitamin A enhances T-helper type 2 cytokine production and secretory immunoglobulin A response to influenza A virus infection in BALB/c mice. J Nutr 2000;130:1132-9.

68. Humphrey JH, Agoestina T, Wu L, et al: Impact of neonatal vitamin A supplementation on infant morbidity and mortality. J Pediatr 1996; 128:489-96.

69. Tielsch JM, Rahmathullah L, Thulasiraj RD, et al: Impact of vitamin A supplementation to newborns on early infant mortality: a communitybased, randomized trial in South India. [abstract] XX International Vitamin A Consultative Group (IVACG) Meeting, Hanoi, Vietnam, 12-15 February 2001. International Vitamin A Consultative Group Secretariat, International Life Sciences Institute Research Foundation, Washington, D.C. 2001.

70. Friis H, Michaelsen KF: Micronutrients and HIV infection: a review. Eur J Clin Nutr 1998;52:157-63.

71. Shankar AH, Genton B, Semba RD, et al: Effect of vitamin A supplementation on morbidity due to Plasmodium falciparum in young children in Papua New Guinea: a randomised trial. Lancet 1999;354:203-9.

72. Coutsoudis A, Bobat RA, Coovadia HM, Kuhn L, Tsai WY, Stein ZA: The effects of vitamin A supplementation on the morbidity of children born to HIV-infected women. Am J Public Health 1995;85:1076-81.

73. Coutsoudis A, Pillay K, Spooner E, Kuhn L, Coovadia HM: Randomized trial testing the effect of vitamin A supplementation on pregnancy outcomes and early mother-to-child HIV-1 transmission in Durban, South Africa. AIDS 1999;13:1517-24.

74. Fawzi WW, Mbise RL, Hertzmark E, et al: A randomized trial of vitamin A supplements in relation to mortality among human immunodeficiency virus-infected and uninfected children in Tanzania. Pediatr Infect Dis J 1999;18:127-33.

75. Hadi H, Stoltzfus RJ, Dibley MJ, et al: Vitamin A supplementation selectively improves the linear growth of Indonesian preschool children: results from a randomized controlled trial. Am J Clin Nutr 2000;71:507-13.

76. Mwanri L, Worsley A, Ryan P, Masika J: Supplemental vitamin A improves anemia and growth in anemic school children in Tanzania. J Nutr 2000 130:2691-6.

77. West CE: Meeting requirements for vitamin A. Nutr Rev 2000;58:341-5. 78. De Pee S, West CE, Muhilal, Karyadi D, Hautvast JG: Lack of improvement in vitamin A status with increased consumption of dark-green leafy vegetables. Lancet 1995;346:75-81.

79. Solon FS, Solon MS, Mehansho H, et al: Evaluation of the effect of vitamin A-fortified margarine on the vitamin A status of preschool Filipino children. Eur J Clin Nutr 1996;50:720-3.

80. Solon FS, Klemm RD, Sanchez L, et al: Efficacy of a vitamin A-fortified wheat-flour bun on the vitamin A status of Filipino schoolchildren. Am J Clin Nutr 2000;72:738-44.

81. Persson V, Ahmed F, Gebre-Medhin M, Greiner T: Increase in serum betacarotene following dark green leafy vegetable supplementation in mebendazole-treated school children in Bangladesh. Eur J Clin Nutr 2001 55:1-9.

82. Fawzi WW, Mbise R, Spiegelman D, Fataki M, Hertzmark E, Ndossi G: Vitamin A supplements and diarrheal and respiratory tract infections among children in Dar es Salaam, Tanzania. J Pediatr 2000;137:660-7.

83. Sempertegui F, Estrella B, Camaniero V, et al: The beneficial effects of weekly low-dose vitamin A supplementation on acute lower respiratory infections and diarrhea in Ecuadorian children. Pediatrics 1999;104:e1.

84. Griffiths JK: The vitamin A paradox. J Pediatr 2000;137:604-7.

85. Semba RD: Vitamin A and immunity to viral, bacterial, and protozoan infections. Proc Nutr Soc 1999;58:719-27.

86. Zhang D, Holmes WF, Wu S, Soprano DR, Soprano KJ: Retinoids and ovarian cancer. J Cell Physiol 2000;185:1-20.

87. Decensi A, Costa A: Recent advances in cancer chemoprevention, with emphasis on breast and colorectal cancer. Eur J Cancer 2000;36:694-709.

88. Ramakrishnan U, Huffman S: Multiple micronutrient deficiencies: what can be done? In: Semba RD, Bloem MW, eds. Nutrition and Health in Developing Countries. Humana Press, Totowa, New Jersey 2001, pp. 365-91.

89. Ahmed F: Vitamin A deficiency in Bangladesh: a review and recommendations for improvement. Pub Health Nutr 1999;2:1-14.

90. Kidala D, Greiner T, Gebre-Medhin M: Five-year follow-up of a food-based vitamin A intervention in Tanzania. Pub Health Nutr 2000;3:425-31. 